\title{
Investigating an Incubator for Digital Innovation in Cultural Heritage
}

\author{
Elin Uppström \\ Uppsala University, Sweden \\ elin.uppstrom@im.uu.se
}

\author{
Carl-Mikael Lönn \\ Uppsala University, Sweden \\ carl-mikael.lonn@im.uu.se
}

\begin{abstract}
In this case study we investigate a cultural heritage incubator, using theoretical constructs suggested suitable for the study of digital innovation in openended value landscapes or ecosystems. Interviews are conducted with eight entrepreneurial firms participating in the incubator, who develop digital innovations within the cultural heritage domain, representatives from museums, also a document study and active participation in incubator activities has been utilized for data collection. A content analysis was conducted using a deductive approach where theoretical constructs from digital innovation literature were used to derive themes connected to concepts of value creation and value capture, value co-creation and co-destruction as well as value spaces paths and recombination. Recommendations are made and the ability of existing theoretical constructs to capture the specific characteristics of the case are made.
\end{abstract}

\section{Introduction}

Digital technologies have the potential to dissolve traditional boundaries and change the landscape where entrepreneurship and innovation processes and outcomes take place e.g., [1]. The characteristics of digital technology also "facilitate greater degree of trial and experimentation in how entrepreneurs go about building their business models, developing and testing solutions, and more broadly addressing new opportunities." [1, p.1041]. This in turn might make traditional theories on innovation and entrepreneurship obsolete [2]. Further, it requires researchers to investigate digital innovation and entrepreneurship using novel theories that have the potential to capture the specific differences brought by digitization and digitalization on innovation and entrepreneurship [3].

In this open-ended digital innovation landscape, where co-creation and networking has become almost mandatory, public organizations are struggling with becoming more open and available through digitalization and open data. This also applies to the Swedish Cultural Heritage Board that is the responsible authority for the preservation, utilization, availability and development of Sweden's cultural heritage. This also includes digitalization and digitization of cultural heritage through and with digital resources.

Furthermore, demands state that all institutions in Sweden that collect, preserve and make cultural heritage materials and information available shall have a plan for digitization and availability. As a part of this endeavor, the Cultural Heritage Board has started an incubator program for small entrepreneurial companies with innovative ideas. This so-called cultural heritage incubator program (the incubator), offers support to entrepreneurs in the cultural heritage domain by facilitating relationship building and providing knowledge support in various forms and different parts of the innovation process. Hence, this initiative has an overall co-creative e.g., [4] effect, i.e., it helps the Cultural Heritage Board to reach the goals regarding digitalization while entrepreneurs get help in realizing their innovative ideas.

Main requirements for entrepreneurs to be accepted to the program was that their innovative idea should address the use, diffusion or availability of the cultural heritage and that digitization or digitalization was a vital component. Many of the entrepreneurs who are part of the program have interesting innovative ideas and digital artifacts that build on technologies such as immersive media, AI, chatbots, storytelling and genealogy.

Calls for research on digital innovation and entrepreneurship include the need for a holistic approach that considers both the individual entrepreneurs and innovations as well as the innovation ecosystem e.g., $[1,5]$. This is also the goal in this research where we study a complete digital innovation ecosystem within the area of cultural heritage in Sweden. In this ecosystem or rather open-ended value landscape [3] prominent actors are the incubator, the entrepreneurs active in the incubator and their innovations, museums and other actors within the cultural heritage domain that represent potential buyers as well as the public, representing end-users. 
In this research we have studied the incubator program, eight of the entrepreneurs in the program, the digital innovation and offerings they are developing and the view of cultural heritage representatives such as museums. Our research shows that creating innovations based on cultural heritage and creating viable and profitable business models that supporting these innovations is challenging. One reason identified is a tension between values of democracy and business.

Our aim in this research is not mainly to theorize value creation, but to provide a novel account of a previously undocumented empirical phenomenon. In this endeavor we use theory of digital innovation through the vocabulary of value spaces [3] to describe the open-ended value landscape surrounding the incubator. We use the concepts of value creation and value capturing $[3,6]$ to reason about issues and possibilities for the entrepreneurs and other actors active in the landscape.

Research on digital innovations and entrepreneurship within the cultural heritage is scarce. This research thereby contributes to this area with insights from a holistic investigation on a digital innovation ecosystem within the cultural heritage domain. Further, this specific open ended value landscape resides in the intersection between private and public sector which in turn create tensions between values of democracy and business. This tension is visible in this case study mainly through the struggles of the digital entrepreneurs to create and maintain viable business models. The case thereby provides the opportunity to investigate how existing theoretical constructs can explain and facilitate the understanding of different aspects present in the case.

We argue that digital innovation theory, represented by the value spaces framework, doesn't account for some of the circumstances found in our investigation, specifically in the imbalances found between the actors in the landscape. Neither does it account for the tension between value capturing and the need for viable business models from an entrepreneurial perspective and the democratization of the cultural heritage through digitalization advocated by the Swedish government.

This paper proceeds as follows; in the next section an extended background is provided. Thereafter we describe the research methods used, after that, the innovations are briefly described. This is followed by the findings, discussion, conclusions and directions for future research.

\section{Extended background}

The extended background gives an introduction to our chosen theories within the digital innovation domain. Further, it provides an introduction to digital innovation in the cultural heritage domain and discusses previous research in digital entrepreneurship.

\subsection{Theorizing Digital Innovation}

In this paper we build on concepts of open innovation as suggested by for instance [7]. However, we choose to rather base our study on the work by [8] and further developed by [9] and [3] who propose that digital innovation takes place in open-ended value landscapes where digital resources are recombined by actors through design and use of digital resources in order to create and capture value.

According to [9] three specific attributes of digital resources impact how we can understand digital innovation; the separation of content and format, the separation of form and function and lastly selfreferencing meaning that digital technology is both the result and the means to develop new digital technology. [9] further suggest the following definition of digital innovation: "the co-creation of novel offerings through the recombination of digital and/or physical components". This is also the definition we adopt in this paper. This choice provides the possibility to discuss digital innovation in the cultural heritage domain from a value co-creation perspective, where digital resources can belong to different value paths [3] depending on how they are reconfigured in use or design. Further, flexible and changeable digital resources that can participate in several value paths become more valuable in comparison to digital resources with only one possible area of use [3]. In accordance with [3] the digital innovations as well as the entrepreneurs developing these innovations are, in this study, considered to exist in an open and changeable landscape. In this open-ended landscape, anyone can also generate and capture value through the transformation of digital resources [3]. The authors also emphasize the benefits of utilizing the notion of digital resources as "entities that serve as building blocks in the creation and capture of value from information" $[3, p$. 2].

\subsection{Digital Innovation in the Cultural Heritage Domain}

The view that digital technology can both transform and be reshaped by creators, users and markets has also influenced research in, for example, tourism, which is a field closely related to cultural heritage. For example, [10] states that the development of digital technologies has changed the tourism sector from a static and utilitarian view, where managers and tourists use 
technology as a static tool, to a transformative view of conceptualization where both the tourism market and its players both shape and are shaped by technology.

[11] emphasizes the importance of adopting a cocreative view of value in archiving, which is said to have a direct significance on the value of the information contained in the archives. The same reasoning can be applied to the large collection of objects at Swedish museums, which admittedly have a value in themselves but which values can be considered to increase if the collections can also be shared and included as resources in different types of networks that create value. There are also other examples of researchers who advocate a greater focus on networking and value creation in the cultural heritage sector. In Italy, [12] believe that the integration of external resources and organizations to increase value creation is an important part of future governance in the cultural heritage sector. [13], also active in Italy, puts forward similar reasoning but with a greater focus on experiences of cultural heritage. The author believes that digitalization has changed the view on democratization the of cultural heritage. From including only passive forms of accessibility for everyone to a participating view where democratization imply that anyone is involved and contributes to managing, creating and experiencing cultural heritage in digital forms [13]. [14] further suggest that the main part of our cultural heritage will be digital in a relatively near future and that it will include for instance computer games.

To investigate how the phenomenon has been captured in digitalization research, we have chosen to focus on the highest ranked journals in the field of information systems (IS) to investigate how cultural heritage has been included in the research area, i.e., the basket of eight magazines called "the basket of eight". A search of Google Scholar in each of these journals resulted in a total of 36 hits on articles that contained the words 'cultural heritage', a review of these 36 articles led to 34 articles being excluded since they considered organizational culture. This leads us to conclude that the cultural heritage has not yet taken a prominent place in IS research and that the digitalization of the cultural heritage has not yet been investigated in IS research.

\subsection{Digital Innovation and Entrepreneurship}

The idea of using incubators to support digital innovation is largely based on ideas about open innovation e.g. [7], where the incubator is part of an innovation support system. Both in research and in practice, the importance of using incubators to create a good breeding ground for and to accelerate digital innovation, combined with sustainable business models, is also emphasized (see for example, [15-17]).
According to [17], there is reason to make other demands on an incubator that will support digital innovation compared with traditional incubator activities. This is also supported by [16] who points out, among other things, that more research is needed on how incubators, that aim to support digital innovation, should be conducted and that the success of these incubators are strongly context-dependent. [1] suggests that existing theories on entrepreneurship are challenged by the development of digital technology, and that new research is needed, especially empirical research that investigate digital entrepreneurship.

\section{Research Method}

In this study we investigated the incubator as a case with a particular focus on ten of the entrepreneurs involved in the program. We used [18, p. 119] definition of case study research: "a research method that involves investigating one or a small number of social entities or situations about which data are collected using multiple sources of data and developing a holistic description through an iterative research process." This section contains the data collection methods used and the method used to analyze the collected data.

\subsection{Data Collection}

[19] recommendation that case study research should use multiple sources of data was followed. Data were collected through twelve in-depth interviews, from secondary sources and from active participation in incubator activities.

The in-depth interviews involved entrepreneurs, incubator management and museum personnel. At the time this study was conducted, seventeen small entrepreneurial companies were a part of the incubator program. We contacted all of these companies and eight entrepreneurs from eight companies volunteered to be interviewed. This sample was reviewed by the incubator management and they regarded these participants as representative and that they would provide a fair view of the entrepreneurs and innovations included in the program.

Three of the in-depth interviews involved employees from three different museums. The interviewed museum employees were selected through purposive sampling [20]. They were selected in consultation with a representative from the incubator management; these respondents have previously been in contact with the incubator and have held presentations at one or more meetings that the incubator arranged for its participating entrepreneurs. Thus, the museum respondents were familiar with the incubator and have 
met some of the entrepreneurs. One in-depth interview involved three representatives from the incubator management.

All twelve in-depth interviews were held via telephone or a web communication tool and lasted between $45 \mathrm{~min}$ and $2 \mathrm{~h}$. The in-depth interviews were conducted by two researchers, most were audiorecorded and then transcribed, in few of the interviews the researchers took notes instead of audio recording. The interviews were semi-structured; three interview guides were used to guide the interviews, one for the entrepreneurs, one for the museums and one for the incubator. The objective with the interviews was to capture their perspective on value creation and value capture as well as co-creation aspects within the openended ecosystem. It should be noted that museums are only a subset of potential users, customers, partners and actors within the open-ended ecosystem.

One of the researchers has also participated in three meetings for participants in the cultural heritage incubator's network. During these meetings the researcher participated in discussions, listened to both entrepreneurial presentations (pitches), as well as external presentations from museums and representatives from the Cultural Heritage Board. Occasions for informal meetings where entrepreneurs were free to talk about their innovations, driving forces, cultural interest and other issues of interest also occurred at these meetings. The researcher participated actively during these meetings by listening and interacting with the participants. The research took notes during the meetings.

Data from the active participation and data from secondary sources was used to complement the interviews. As secondary material, we collected descriptions and evaluation reports of the incubator program and activities and market evaluation reports.

\subsection{Data Analysis}

The qualitative data were subjected to content analysis [21]. The data analyzed in the first step of the coding were transcriptions from the in-depth interviews. The analysis was carried out jointly by both authors. The data were analyzed iteratively, with continuous cycles of research and reflection. [22] cautioned against an overly rigid approach to coding and encourage researchers to continue changing both codes and sorting methods as the analysis progresses and these recommendations were taken into consideration during the coding processes. Each sentence in the transcriptions was re-organized into chunks of text with specific meanings and then each chunk was marked with one or several initial codes. Changes and refinements of the initial codes during the coding process was allowed, in accordance with the advice of [22]. Example of codes are values, challenges, actors, collaboration. This iterative coding process continued until all data had been coded. Excel was used to code the data and sorting functions were used to sort the codes into categories.

\section{The Innovations}

Innovation 1, this idea has emerged from the frustration that there are thousands of digitized historical maps available but to find and access them requires a lot of effort, further the maps are not interactive. The innovator's idea is therefore to make these maps more accessible and to adopt technology from gaming to make the maps more interactive and exciting.

Innovation 2, uses photometry to digitalize physical cultural heritage objects in the form of authentic digital high-resolution models. Thereby providing new opportunities to study ancient monuments such as runestones and to discover new details and information that have not been possible to see on the physical objects. Further, exact measurement tools have been developed as well as rigs that automate the actual photography of objects.

Innovation 3, is an experience-based genealogy tool inspired by gaming. The innovation is in a testing stage and has around 800 registered test users. A user community has also been created that has a saying about which functionality to include in the service. The service also retrieves open data from several different databases, for example The National Land Survey authority in Sweden, to retrieve both historical and contemporary maps. The focus is also on storytelling and content from the cultural heritage.

Innovation 4, is an AI tool to personalize and chat with historical persons. These so called, cognizens has been implemented to have a personality. Achieving this personality requires advanced technology but also content in the form of anecdotes, descriptions and other information about historical figures. Today, the development has led to the creation of a platform for creating characters that are aware of the present as well as their own history, using a modeling tool.

Innovation 5, enables storytelling through the use of various digital media such as augmented reality (AR), virtual reality (VR) and 360 video formats, so-called immersive media. The company has been around for a few years and worked with several different industries before joining the incubator. One reason highlighted by the respondent is that the cultural heritage sector, and not least museums, is a natural scene for storytelling.

Innovation 6, recreates historical environments with the help of AR and VR, you can walk around in and discover what it looked like in the past. Advanced 3D-technology and game graphics are used. The 
company has also built an archery game where the experience is to walk around and shoot enemies in a rendered old town.

Innovation 7, is a platform, similar to Instagram and YouTube but for digital storytelling. Anyone can create stories and post them on the platform. The app uses Google Maps to link the stories to places on the map. Various types of additional services are linked to the platform, such as professional content creation support.

Innovation 8, is similar to innovation 7, a digital storytelling service that also include open data with geotags, for instance, information about historical sites or musical pieces connected to a place.

Most of the digital innovations have a strong focus on experience and content. Regarding experience, there are examples of a number of different techniques that are used to create a strong experience such as AR, VR and other immersive media. The cultural heritage is the basis for the content of several of the innovations. The cultural heritage is refined to varying degrees to adapt to the innovations. We also see examples of content in the innovations being created continuously by various actors. For example, storytelling where stories are published continuously by the entrepreneurs and also the opportunity for users to contribute content and thereby create cultural heritage. The innovative aspects in the digital innovations are thereby to a large extent the combination of experience and content. The third component in a digital business model [23], platform, is less prominent. Many of the entrepreneurs instead utilize existing digital technologies such as Google Maps. Some entrepreneurs have chosen to invest in advanced and innovative technology such as VR, which at the same time drives large development costs. There are also innovations that use advanced data analysis and machine learning, something that has been shown to involve large investments. Innovations that combine different data sources with open data, to offer a rich content that primarily comes from different cultural heritage institutions and authorities, is also present.

\section{Findings}

\subsection{Value creation}

This section presents the most prominent value propositions that the interviewed entrepreneurs envision with their digital innovations. A value proposition is here viewed as a potential value that can be realized, for example through the use of a product or service.

5.1.1. Increased Availability. The cultural heritage can, using digital resources, be experienced anywhere and at any time. This as opposed to for instance a physical museum that is bound to a physical place and has specific opening hours. More people can experience the cultural heritage, for instance through guidance and storytelling at times and places where it was not possible before. Digital cultural heritage thereby becomes available to more people and new target groups.

There are also parts of the cultural heritage that are not accessible or do no longer exist. For example, collections may be in a sensitive and/or inaccessible environment; a wreck located on the seabed, or a city, a grave or a building that has been lost over time. These artifacts can be reconstructed digitally and thereby available through digital means. This is highlighted by an entrepreneur who believes that it is in principle impossible to physically reconstruct certain places. With digital technologies such as AR and VR, however, it is still possible to reconstruct an entire city or place (e.g., innovation 6).

Availability also concerns large collections with many objects that remain in archives that are not accessible to the public. Through digital representations, they are made available. An entrepreneur points out that this is one of the strongest driving forces for them to work with immersive media: "We want to work with the hidden stories that you may not have the time or opportunity to get into the regular exhibitions, there are lots of things that do not fit in the regular setting".

This also applies to runestones that are digitized (innovation 2), when digitized it is possible to study the stones without affecting them. Also, broken parts can be assembled digitally, which means that lost information can be recreated.

5.1.2. Make visible, reinforce and create. One purpose with several of the digital innovations is to make the cultural heritage visible. As one of the entrepreneurs puts it: "If we do not do this digitally, the culture will disappear".

There are also examples of digital innovations that aim to enrich the experience of the cultural heritage. E.g., the cultural heritage is made visible through digital storytelling in innovation 7 and 8 . Immersive media is used to enhance experiences at specific museums and sites in innovation 5.

Another value offered by some innovation (e.g., 7 $\& 8)$ is the creation of cultural heritage. For instance, stories that are not collected and preserved by any cultural institution. It can for example be stories told or written down by relatives and now publishable using digital resources. This possibility provides anyone with at least some digital skills the opportunity to participate in the creation of digital cultural heritage.

5.1.3. Enhance Knowledge and Learning. Several of the digital innovations aim to enhance the understanding 
of the cultural heritage. By creating a holistic view of a historical event through combining information from different sources or different perspectives (e.g., innovation 4), by representing objects in their real context with the help of VR or AR (innovation 5). Several entrepreneurs also aim to make the cultural heritage more comprehensible through their innovations. An entrepreneur believes that a captivating story that is easy to understand can be created by using different types of digital technologies.

Several of the innovations contribute to dissemination of knowledge and learning related to history and cultural heritage. Examples include, through stories about different places and events or through a VR walk in a historical place. Several digital innovations also have the potential to be used as teaching materials in schools, e.g., to be able to talk or chat with Albert Einstein about the theory of relativity, (innovation 3) learn about history (e.g., events and places) through living stories, (innovations $7 \& 8$ ) or experience historical places in VR (innovation 5).

There is also hope among some entrepreneurs that history and archeology "can act as an eye-opener for sustainability thinking in the long run" thereby contributing to sustainability. If you understand and experience what it looked like in a place at different time, it potentially creates an awareness about long time perspectives and it can in turn contribute to decisions becoming more long-term and creative.

5.1.4. Improve Preservation. There are examples of digital innovations that contribute to the preservation of cultural heritage, e.g., by documenting and recording stories related to the cultural heritage (innovation $7 \&$ 8). This applies to a large extent to contemporary history when, for example, individuals can record their own story and post it on a platform.

Through digitization, cultural heritage can also be preserved. This is especially important for objects that are difficult to preserve in its physical form. Preserving these objects digitally thereby prolongs their life.

\subsection{Value Capturing}

Several differences are noted in relation to the business models of the entrepreneurial firms. Maturity is one aspect that varies. It is difficult to assess how and if the different business models will be sustainable in the long run since the innovations have not yet stabilized. However, we do see a couple of challenges that impede the capturing of value, these challenges mainly concern customer segments and revenue streams. Further, there is a tension between the will of the Swedish government to democratize the cultural heritage and make it available through means of digitalization and the need of the entrepreneurs to develop sustainable business models and make money.

5.2.1 Customer Segment. Who you sell to and how to sell to them is something that all interviewed entrepreneurs discussed. Some of the entrepreneurs have a B2B strategy, e.g., public organizations and museums, others target consumers, there are also examples of companies including both businesses and end customers in their strategy.

Several of the entrepreneurs point out that it is difficult to identify markets and customer segments for their offerings. Some of them have experimented with reaching specific customer segments. One example is an entrepreneur who mentions that they thought about creating teaching materials and thus target teachers and schools. The idea was well received by teachers, "we thought we would try to get teaching materials, so we tested on some teachers, and they were completely lyrical and wanted it". However, when contacting a publisher, the small budget for developing teaching material became an obstacle.

Another example of entrepreneurs struggling with defining their target market is an entrepreneur whose innovations are based on VR. The entrepreneurs have noticed that an older target group tests the innovation, but it is difficult to determine whether it is the interest in history or the technology itself that creates an interest and whether the elderly is a potential segment or not.

For some of the companies the targeted customer is more obvious and others already have a user group that pays for similar services. For some of the innovations, however, it is unclear who is the end user and who will finance the use of the innovation. Several entrepreneurs think that cultural heritage institutions and other actors, such as museums and schools, should pay for the digital innovations, since it will be used by their customers. But this is challenging for several reasons, for example, several representatives from museums state that they have a strained budget and that it is risky to work with small actors. Common to all public institutions and organizations is also that the decision paths are long and that the law on public procurement does not allow long commitments without new exposure to competition. The differences in time perspective are perceived as frustrating by several entrepreneurs. This is illustrated, for example, by the following quotation: 'People really want it, but they have to put it into a budget that will become a reality in two years. For a startup, two years is perhaps death. It's too long."

Several of the entrepreneurs also point out that there is a skepticism towards companies in the cultural heritage sector and in authorities. "Even authorities that are going to buy a service are very skeptical. And they cannot imagine paying what it costs for a digital 
service." From the museum side, there is a certain skepticism towards both innovations and small entrepreneurs, since they do not live up to demands of long long-term perspectives required by museums. There is also a problem in that several cultural heritage institutions do not have a digitalization budget.

5.2.2 Revenue Streams. Several entrepreneurs highlight a problem with creating revenue streams, in other words that it is difficult to charge for their innovations. Some believe this may be due to an expectation in Sweden that the cultural heritage should be free for everyone. The same problem is found when it comes to creating revenue streams from digital services, such as apps or content, since many consumers are used to digital services being free of charge due to financing through advertising. One company considers increasing their revenue streams through advertising, but they are hesitating since they think that advertising will make their digital innovation less esthetic. Further, it is regarded as inappropriate to have advertising in cultural heritage services.

One entrepreneurial firm innovation (3) differs from the others in regards to difficulties of creating revenue streams. They use a subscription model, which is a payment model that their customer segment is already used to.

To expand their customer base and strengthen their revenue streams, several of the entrepreneurs have expanded their offering, which can be in the form of completely new products/services or by adding additional services or products to their basic offer. One of the companies offers their basic platform for free, and then has additional services that they can charge for (innovation 7). For example, edit, upload and manage content. They have had a clear platform strategy from the beginning where the basic functionality is free and revenue streams come from offering of additional services. A challenge for them is to understand what these additional services should be.

\subsection{Co-creation within the Open-ended Value Landscape}

The open-ended value landscape where the studied innovations and entrepreneurs are placed also consists of several other actors, such as museums and other cultural heritage institutions and public organizations such as municipalities and regions. Other important actors in this context are the public, or end users. These can be, for example, tourists, but also citizens, who use apps and participate in cultural experiences. In a report from the Cultural Heritage Board on the economic significance of cultural heritage, the hospitality industry is highlighted as one of the most important sources of economic growth in the cultural heritage domain. We also see that non-human actors have an important part in the landscape such as places (museums, culturalhistorical relics), physical objects and digital resources, this is in line with [3] view on an open-ended innovation landscape. A prominent digital resource in several of the innovations is Google Maps used as a platform to deliver a map-based service. Cultural heritage data in digital form, made available as open data, is often an important part of the digital innovations. Hence, the institutions that create and make this data available can be seen as suppliers in the landscape.

Engaging in open innovation within this landscape is also something all entrepreneurs state as something necessary. Actors such as museums also see the benefits in co-creating value together. One example is the creation of a structured community for users where a constant dialogue can take place as new functionality is released and tested. Another is the interest from museums to have digital entrepreneurs working at the museum facilities and developing solutions for digital cultural heritage together with the museum.

Most entrepreneurs also demand more support from the incubator in forming good collaborations with actors in the cultural heritage sector. At the same time, the majority believe that it is precisely as a bridge between the entrepreneurs and the cultural heritage sector that the incubator has been of great help.

Several of the innovations (e.g., $3 \& 8$ ) use open data, this open data is refined, enriched and combined. The data can be anything from collections of objects, map data or pieces of music. As this data is available, the potential to realize many different values is created. When there is a demand for open data, the incentives of various cultural institutions to make data available as open data also increase, thus facilitating co-creation.

There are also challenges present within the landscape, unbalance between actors is one, both in terms of knowledge and economics. Today, the cultural heritage sector is perceived to be at a lower level of digital maturity compared to the entrepreneurs. This creates difficulties for entrepreneurs to communicate on how their digital innovations create value. Another aspect that entrepreneurs experience is a focus on physical places that become limiting and lead to difficulties in communicating the inherent nature of digital innovations, that they are not limited by time and space. This feature enables experiences outside of physical locations that may also have limited opening hours. At the same time museums represent a special place that can enhance experiences, also digital ones.

Another issue within the landscape is that museum and cultural heritage institutions often act as both suppliers and buyers, they provide content in the form of open data (which is freely available), and are then 
expected to buy services built on their own open data. This could potentially create frictions between actors.

Further, this implies that openness might not always be a goal in itself, openness can also risk damaging relationships and also lead to co-destruction of value i.e., that engaging in collaboration within an open-ended landscape leads to loss of values, at least for some actors. Another aspect of openness, leading to similar issues of co-destruction, but for entrepreneurs is also present in the open-ended landscape. By using open data to create content for their digital resources, these digital resources become easy to copy, thus risking the novelty of their business model due to competition.

It is clear in our research that large infrastructure and service providers, such as Google, are winners also when digital innovation takes place within the cultural heritage domain. Their digital resources are used in several innovations, thereby creating opportunities for their digital resources, such as google maps, to participate in more value paths. Does this necessarily mean that these digital resources are contributing value? In the theoretical construct of value spaces [3] the answer would be yes. Google of course captures value and also creates value by offering the entrepreneurs to use digital resources like google maps. We would however also regard this usage as a potential risk in regards to, for example, privacy and democratization, something that should be further investigated in future research.

A context specific aspect within the landscape that is also contradictory is the conflict between mass and high culture. Several of the entrepreneurs also experience a conflict between creativity and profitability. The notion of high culture implies that culture should be difficult to access and understand to be of high value, which is in direct contrast to the values highlighted in digital innovation, such as openness, availability and accessibility.

An expectation expressed by the entrepreneurs and museums is that digital innovation will help to diminish the line between high and mass culture and thereby reduce this contradiction. However, there is also a concern that culture will lose significance if it becomes too mass-produced and easily accessible and that focus will shift to producing only culture for the large masses.

\section{Practical Implications and Recommendations}

An incubator, providing support for digital innovation, should focus on openness and co-creation of value between actors. Activities within this area are the most appreciated by all actors present in the open-ended value landscape of cultural heritage. An incubator should facilitate the digital innovation processes by focusing on providing support that: (i) create opportunities to utilize existing digital artifacts in new ways, (ii) make it easier for entrepreneurs to create new collaborations with different actors, (iii) create opportunities for digital resources to participate in new value paths. Further, highlighting and investigating possible value spaces where digital resources can create or increase existing values by being combined with other digital resources should be a focus.

Support is also needed in balancing the need for transparency in relation to control over one's own innovation process and its results, as well as maintaining unique parts that cannot be easily copied by others. Awareness and understanding about the inherent characteristics of digital resources are required. One example is that digital innovations emerge in iterations and do not reach a status as 'finished'. Instead, throughout their life cycle. they can be reshaped and changed by the innovator as well as by users, partners and completely unknown actors. This means that the main focus should be on the process and not as much on finished products and services, i.e., how you as an entrepreneur work with digital innovation rather than the result. This affects how a digital innovation should be valued, which should affect how the incubator is evaluated. The focus when evaluating the incubator should be on how well it succeeds in facilitating and establishing collaboration in different forms and with different actors rather than on how many successful digital artifacts are launched on a market.

Digital resources should, according to our theoretical lens e.g., [3] be reconfigurable, have several potential uses and not be aimed specifically at solving individual problems with specific functionality; this could be a potential criterion for choosing digital innovations that will receive support by the incubator in the future.

We also find support in our recommendations in [17]. Their reasoning about incubators and digital innovation have also highlighted similar aspects, however within a completely different sector, the automotive industry.

\section{Discussion}

\subsection{Value Creation and Value Capturing}

As shown in the findings section, a potential for value creation through the different digital innovations active in the incubator are present. [9] and [3] state that the potential of value creation is greater when digital resources are able to be part of more value paths. Our findings support this notion to some extent. An example is that those digital innovations who aspire to act as platforms, where different actors can provide content 
seem to have a greater potential for value capturing. Thus, the framework of recombination is valuable in order to understand some aspects of how to navigate in the open-ended landscape of digital innovation. However, there are still aspects missing that can explain how the open-ended landscape functions and how to navigate in it. Some of these aspects seem to be related to the context, i.e., cultural heritage, while others are related to the implicit notion of digital innovation; that openness is always a good thing. In this research we have shown that openness also brings certain difficulties and potential for co-destruction of value.

Another problematic aspect visible in this study is in the nature of the value creation in the digital heritage domain; access to cultural heritage is by many considered to be a civic right which should be free of charge. The same can be said about digital content, since it is often being produced by end-users it is not paid for.

Several entrepreneurs highlight issues with creating sustainable revenue streams, some believe this may be due to an expectation that the cultural heritage is free of charge, this could however be questioned since it is not uncommon to pay for access to for instance museums and other venues displaying cultural heritage objects. Another reason is that consumers, or end-users are used to digital content and apps depending on revenues from commercials instead of paying customers.

The issues and contradictions presented within the cultural heritage open-ended digital innovation landscape are not easily captured using the value spaces [3] construct. The framework seems to imply that value is always created when digital resources are reconfigured and also that the more possibilities for recombination, the greater the potential for value creation. This does, however, to a large extent depend on how value is viewed. We have shown that although the studied digital innovations create values, it is still very difficult for the entrepreneurs to capture value and turn it into profit. To be open, collaborative and to develop reconfigurable digital resources with potential to participate in different value paths does not seem to be a certain success within the digital heritage domain. We can even see that openness can become an obstacle for several of the actors. There is a tension present between public values such as democracy, and viable business models needed for entrepreneurs to develop digital resources within the cultural heritage domain.

This further implies that the theoretical constructs available to us to theorize digital innovation does not take these complex issues of contradiction into account. How do we model power and knowledge imbalances within an open-ended landscape and how do we capture the opposite of co-creation, i.e., co-destruction? This would be an interesting venue for future research.
Further, we see a difference between the different layers of digital resources [8]. In this research the digital resources that seem to be able to capture value and thereby make it possible to also have a sustainable business model, belong to the first three layers where it is possible to balance openness and integrity. On the highest layer, the content layer, it seems to become more difficult to create digital resources that are recombinable and can participate in different value paths. It is also more difficult to get paid when the content is open, which demands the entrepreneur to create content. This is also the case in large it-businesses providing content as their main offering e.g., Netflix. Today Netflix relies to a large extent on creating content, instead of only providing it to the end-customer.

\subsection{Value Spaces}

Compared to the original use of value spaces, to investigate digital resources and recombination when the digital resource is in use, we rather focus on the other side, i.e., the recombination in design, which has also been investigated previously [4]. However, we also include one aspect of recombination in use since we capture the view of the demand side in the form of museums. The value spaces framework [3] has been used to characterize the digital innovations. Most of them belong to the content and to some extent the service level. The device and network layer is covered by combining digital resources from other actors, mainly Google but also Apple, Android and different types of hardware for VR, AR and immersive media.

\section{Conclusions}

We have in this research shown that digital innovations with great potential for value creation have been designed within an open-ended ecosystem and also that the incubator has played an important role as support and facilitator. Further, issues and imbalances have been shown to exist within the landscape.

Practical contributions and recommendations are suggested on how an incubator within the cultural heritage sector can facilitate digital innovation and we would argue that they are to some extent also viable for other sectors who participate in open-ended value landscapes, especially in the intersection between private and public sector. Further, issues present due to the specific characteristics of the landscape are highlighted and discussed.

In the theoretical domains our research has shown that current theoretical constructs are helpful when investigating digital innovations but that it is difficult to capture contradictions and imbalances present in the landscape, as well as negative aspects of some values. 
Some of these issues are related to the context of the cultural heritage domain, some due to the intersection between private and public and also issues related to the balance between openness and uniqueness. If we want digitalization of cultural heritage to also facilitate democracy, how should the open-ended value landscape look like?

\section{Future Research}

Future research should further investigate the recombination in use perspective by investigating the end-user perspective of the designed innovations in the form of digital resources. This research points out that theoretical constructs are needed that can facilitate understanding and modeling of the complexities present in open-ended value landscapes. In these landscapes values are not mainly economic but instead social and the actors are both private companies and public organizations as well as policy makers. Future research could therefore focus on developing such constructs.

\section{References}

[1] S. Nambisan, "Digital entrepreneurship: Toward a digital technology perspective of entrepreneurship. Entrepreneurship theory and practice", 2017, 41(6), pp. 1029-1055.

[2] E. S. Berger, F. von Briel, P. Davidsson, and A. Kuckertz, "Digital or not-The future of entrepreneurship and innovation: Introduction to the special issue", 2021.

[3] O. Henfridsson, J. Nandhakumar, H. Scarbrough, and N. Panourgias, "Recombination in the open-ended value landscape of digital innovation". Information and Organization, 2018, 28(2), pp. 89-100.

[4] V. Grover, and R. Kohli, "Cocreating IT value: New capabilities and metrics for multifirm environments. Mis Quarterly", 2012, pp. 225-232.

[5] S. Nambisan, M. Wright, and M. Feldman, "The digital transformation of innovation and entrepreneurship: Progress, challenges and key themes". Research Policy, 2019, 48(8), 103773.

[6] A. Osterwalder, and Y. Pigneur, Business model generation: a handbook for visionaries, game changers, and challengers, John Wiley \& Sons, 2010.

[7] H. W. Chesbrough, and M. Appleyard, "Open innovation and strategy". California management review, 2007, 50(1), pp. 57-76.

[8] Y. Yoo, O. Henfridsson, and K. Lyytinen, "The new organizing logic of digital innovation: An agenda for information systems research". Information Systems Research, 2010, 21(4), pp. 724-735.
[9] P. Hukal, and O. Henfridsson, Digital innovation - a definition and integrated perspective. In The Routledge companion to management information systems, Routledge, 2017.

[10] M. Sigala, "New technologies in tourism: From multidisciplinary to anti-disciplinary advances and trajectories". Tourism Management Perspectives, 2018, 25 , pp. $151-155$.

[11] R. Mukhlesur, Resource Integration for Value Cocreation in Archival Service Ecosystem. Doctoral Dissertation, Graduate School of Advanced Science and Technology Japan Advanced Institute of Science and Technology, 2019.

[12] S. Barile, and M. Saviano, Resource integration and value co-creation in cultural heritage management. In Handbook of Research on Management of Cultural Products: E-Relationship Marketing and Accessibility Perspectives, IGI Global, 2014.

[13] E. Bonacini, "Participation and Co-creation of Cultural Values: The\# izi TRAVELS icilia Project". Museum International, 2018, 70(1-2), pp. 140-153

[14] J. Suominen, and A. Sivula, "Gaming legacy? four approaches to the relation between cultural heritage and digital technology". Journal on Computing and Cultural Heritage (JOCCH), 2013, 6(3), pp. 1-18.

[15] J. L. Barbero, J. C. Casillas, M. Wright, and A. R. Garcia, "Do different types of incubators produce different types of innovations?". The Journal of Technology Transfer, 2014, 39(2), pp. 151-168.

[16] S. Mian, W. Lamine, and A. Fayolle, "Technology Business Incubation: An overview of the state of knowledge". Technovation, 2016, 50, pp. 1-12.

[17] A. Hjalmarsson Jordanius, G. Juell-Skielse, and A. Kailas, "Digital innovation and incubators: A comparative interview study from the perspective of the automotive industry". In Proceedings of the 52nd Hawaii International Conference on System Sciences, 2019.

[18] G. Easton, "Critical realism in case study research. Industrial marketing management”, 2010, 39(1), pp. 118128.

[19] R. K. Yin, Case study research and applications: Design and methods, Sage publications, 2017.

[20] M. Denscombe, EBOOK: The Good Research Guide: For Small-Scale Social Research Projects. McGraw-Hill Education (UK), 2017.

[21] K. Krippendorff, Content Analysis: An Introduction to Its Methodology (3rd ed.). Thousand Oaks, CA: Sage Publications, 2012.

[22] J. Saldaña, The coding manual for qualitative researchers, Sage publications, 2021.

[23] P. Weill, and S. L. Woerner, "Optimizing your digital business model”. MIT Sloan Management Review, 2013, 54(3), 71. 